\title{
EPISTEMOLOGÍA Y HERMENÉUTICA: ENTRE LO CONMENSURABLE Y LO INCONMENSURABLE
}

\section{EPISTEMOLOGY AND HERMENEUTICS: BETWEEN COMMENSURABILITY AND INCOMMENSURABILITY}

Dra. María de la Luz Flores-Galindo (floresgalindoluz@yahoo.com.mx). Colegio de Humanidades y Ciencias Sociales. Universidad Autónoma de la Ciudad de México (México).

\begin{abstract}
Traditionally epistemology and hermeneutics have been separated, since the first deals with commensurability and the second with incommensurability. Nevertheless, in my opinion, nowadays it is possible to unite epistemology and hermeneutics if we start from a theory contemporary epistemology: the theory of the truth as rational acceptability in optimal epistemic conditions. This theory allows us to justify commensurability and to understand incommensurability.
\end{abstract}

Key words: epistemology, hermeneutics, truth, commensurability, incommensurability.

\section{Resumen}

Tradicionalmente se ha separado a la epistemología y a la hermenéutica, puesto que la primera trata de lo conmensurable y la segunda, lo inconmensurable. Sin embargo, en mi opinión, hoy en día es posible unir a la epistemología y la hermenéutica sólo si partimos de una teoría de la epistemología contemporánea: la teoría de la verdad como aceptabilidad racional en condiciones epistémicas óptimas. Dicha teoría permite justificar lo conmensurable y entender lo inconmensurable.

Palabras clave: epistemología, hermenéutica, verdad, conmensurable, inconmensurable.

\section{Introducción}

Frecuentemente ha se acusado a la hermenéutica de irracionalidad, pues Rorty en La filosofía como espejo de la naturaleza establece que la forma habitual de tratar la relación entre hermenéutica y epistemología es sugerir que se dividan la cultura entre sí: la epistemología se ocuparía de la parte seria e importante, aquélla con la cual cumplimos las obligaciones con la racionalidad y, en cambio, la hermenéutica, de todo lo demás. Lo que está de fondo en esta división es que el conocimiento, en sentido estricto, episteme, debe tener un logos que sólo puede estar dado por el descubrimiento de un método de conmensuración. Así pues, la idea de conmensurabilidad está incluida en la noción de cognición auténtica, por lo que las cuestiones de gusto, o 
de opinión, no tienen por qué caer dentro de la epistemología; y, por el contrario, lo que la epistemología no puede hacer conmensurable se desprecia como meramente subjetivo.

La acusación de irracionalidad en la hermenéutica, por otro lado, establece Vattimo, en Más allá de la interpretación, se formula mediante una noción débil de racionalidad, entendida como la capacidad de proponer argumentos públicamente reconocibles, en vez de simples intuiciones poéticas. Así pues, lo epistemológico es lo que Kuhn llama ciencia normal, mientras que lo hermenéutico es sólo el encuentro con un sistema de metáforas, con un nuevo paradigma, cuya comprensión y aceptación nada tienen que ver con el procedimiento demostrativo, si acaso, con la argumentación persuasiva.

Frente a esta división entre epistemología y hermenéutica, y contra las acusaciones de irracionalidad hacia la hermenéutica, propongo que tanto la epistemología, como la hermenéutica filosófica utilizan criterios de racionalidad semejantes, tanto para establecer lo conmensurable, como para comprender lo inconmensurable. $Y$ es que, en la epistemología contemporánea, se ha propuesto la teoría de la verdad como aceptabilidad racional que utiliza el criterio de verdad como adecuación y, dicha teoría, ofrece una solución a los problemas de comprensión entre individuos de marcos conceptuales diferentes mediante el diálogo, la interpretación, en lugar de la traducción y acuerdos racionales. Asimismo, la hermenéutica filosófica ha propuesto una noción de verdad basada en el criterio de adecuación y resuelve el problema de la comprensión de marcos inconmensurables mediante el diálogo, la interpretación y la discusión racional. En consecuencia, lo que podemos observar es que ambos campos del conocimiento utilizan criterios de verdad y racionalidad semejantes, por lo que ya no se sostiene la tradicional división entre epistemología y hermenéutica.

A fin de mostrar lo anterior, presentaré cuatro secciones: en la primera, algunos argumentos para sustituir a la epistemología por la hermenéutica; en la segunda, las razones por las cuales había sido imposible unir epistemología y hermenéutica; en la tercera, la verdad como adecuación, tanto en la epistemología como en la hermenéutica; y en la última, la unión entre epistemología y hermenéutica.

Las limitaciones de este trabajo consisten básicamente en tomar como modelo de análisis en la epistemología, para el tema, exclusivamente a la teoría de la verdad como aceptabilidad racional, precisamente porque es congruente con el punto de vista de la hermenéutica filosófica. Sin embargo, esta congruencia me parece muy acertada y de lo más racional que existe hasta el momento, en mi opinión, dentro de la epistemología contemporánea, ya que permite comprender tanto lo conmesurable como lo inconmensurable. Veamos.

\section{Argumentos para sustituir a la Epistemología por la Hermenéutica}

La figura filosófica que está detrás del retorno a la historia es Richard Rorty en La filosofía como espejo de la naturaleza. De acuerdo con Rorty, la noción de conocimiento, como representación precisa, posible gracias a procesos mentales especiales e inteligible mediante una teoría general de la representación, tiene que ser abandonada.

Asimismo, sostiene que la historia del conocimiento no ha sido un mejoramiento progresivo en las capacidades de representación que tiene la mente, conforme ésta ha tratado de hacerse más transparente ante sus objetos. Sino que más bien, conocer ha sido participar en diálogos diversos, cambiantes, que han utilizado vocabularios diferentes para abordar intereses distintos, así como tratar preguntas diversas. 
También ha señalado que la historia de la filosofía no es un conjunto de soluciones precisas a problemas, sino una serie de conjuntos enteramente distintos de problemas y que el vocabulario reciente no expresa necesariamente representaciones privilegiadas de esencias, sino tan sólo uno más del infinito potencial de vocabularios en los que el mundo puede ser descrito (Rorty 1979:13).

Así pues, la epistemología no puede erigirse con una jerarquía por encima de las demás disciplinas, pretendiendo ser la disciplina más básica, cuya tarea consiste en establecer la objetividad de la justificación de conocimiento formulada en diversas disciplinas científicas. Y es que la filosofía se ha integrado a través de diversos tipos de análisis, que pueden o no ser de interés para individuos de otros campos, mismos que no pueden pretender establecer las reglas básicas por las que deben regirse.

En la diversidad de mundos y de modos de pensar y expresarse, no tiene sentido tratar de promulgar leyes acerca de cómo debería funcionar la mente, puesto que proceder de esa manera, sería proponer sólo otra manera de interpretar el mundo y hablar acerca de él, pero no del modo de poner fin a todas las maneras de expresarse. Por lo tanto, aconseja Rorty, no deberíamos tratar de crear un modelo mejorado de la mente, sino examinar la documentación histórica para saber cómo surgieron los diversos problemas del conocimiento. Así pues, resolver estos problemas no implica elaborar un discurso de la representación del mundo, sino de la comprensión del diálogo de filósofos que plantearon problemas (Rorty 1979:132-135).

Por esta vía de razonamiento, Rorty concluye que deberíamos abandonar la epistemología. Por epistemología entiende el proyecto de aprender más acerca de lo que podríamos saber y cómo podríamos saberlo mejor mediante el estudio de cómo funciona nuestra mente. Y es que este proyecto epistemológico resulta dudoso si no hay una sola manera correcta de conocer. Sin embargo, este es un proyecto de redefinir la epistemología en lugar de soslayarla.

Es así que la petición de Rorty de abandonar la epistemología resulta contradictoria en sí misma, ya que una teoría del conocimiento está implícita en su descripción de las disciplinas como conversaciones diversas, cambiantes.

Al negar que la comprensión es representación precisa, Rorty especula que adopta otras formas: la búsqueda de creencias intersubjetivamente aceptables y de argumentos convincentes. Que ésta sea una explicación satisfactoria o no del conocimiento es una cuestión epistemológica, y parte de la respuesta que se le dé exige un examen de su afirmación que debiéramos considerar la justificación más como fenómeno social que como transacción sobre el objeto de conocimiento y la realidad (1979:9).

Como lo plantea Rorty: ¿no hay limitantes perdurables sobre lo que puede considerarse conocimiento, o hay pruebas transhistóricas de validez? ¿Es suficiente considerar los criterios de interpretación como enteramente internos a la comunidad, o debiéramos preservar cierto concepto de alteridad como el objeto del que los intérpretes son responsables y al que se orientan sus diversas conversaciones, aunque dicha alteridad pueda variar radicalmente, según como se le interprete? Estos son algunas de las interrogantes epistemológicas planteadas por el ataque que Rorty dirige a la epistemología.

En mi opinión, las limitantes del conocimiento, debidas a la insuficiencia de la epistemología para comprender diversas visiones del mundo pueden resolverse si aceptamos unir epistemología con la hermenéutica. Lo interesante es que dicha unión ya existe en una teoría de la epistemología contemporánea, la teoría de la verdad como aceptabilidad racional. En ésta, la epistemología se ocuparía de 
los criterios de interpretación internos a una comunidad epistémica; mientras que la hermenéutica, complementaría a esta teoría al tratar de comprender la alteridad de otras visiones del mundo.

A continuación mostraré cuáles son las razones por las cuales ha resultado imposible unir a la epistemología con la hermenéutica; posteriormente, presentaré cómo es posible unir a la epistemología con la hermenéutica; por supuesto, dentro de la teoría de la verdad como aceptabilidad racional, que en sí misma es epistemológica y hermenéutica.

\section{Imposibilidad de unir epistemología y hermenéutica}

La separación clásica entre epistemología y hermenéutica proviene de la separación galileana entre ciencia y filosofía. La confianza en el método científico y el experimento excluye cualquier tipo de racionalidad (Gadamer 1985). En el siglo XX, el empirismo lógico y el racionalismo crítico establecieron como criterio de racionalidad científica sólo el contexto de justificación. Así, cualquier tipo de proceder científico que no se adecuara a dicho contexto era considerado irracional.

Además, las teorías que excluyen a la racionalidad prudencial y sólo establecen la racionalidad epistémica están cimentadas sobre un modelo fundacionista del conocimiento, mientras que sólo a partir de tomar en serio la tesis de la inconmensurabilidad kuhniana es posible pensar en la unión entre epistemología y hermenéutica.

Las tesis básicas de todo fundacionista, que pretende tener un acceso privilegiado a lo real, son: a) es posible alcanzar algún tipo de conocimiento cierto, indubitable como punto de partida para el genuino conocimiento y b) hay un método que garantiza los resultados del proceso cognoscitivo (Di Gregori 1995:4142).

La tradición del fundacionismo, con las palabras de Sosa, considera que: "la realidad objetiva nos provee no sólo de objetos de conocimiento, sino también de puntos de partida y métodos obligatorios. Estos puntos de partida y métodos obligatorios definen una estructura ahistóricamente permanente que determina el uso legítimo de la razón, y fija las condiciones y extensión de la racionalidad, el conocimiento, el bien y el derecho" (Sosa 1988:351-352).

Estas corrientes fundacionistas no tienen cabida para la racionalidad prudencial, debido a la noción de objetividad que ellas entienden, pues suponen una realidad objetiva que impone a la razón sus límites y su extensión, así como los métodos para conocer los hechos de esa realidad: se trata de "la tradición platónica comprometida con una realidad objetiva cognoscible por la mente pero independiente de ser conocimiento o siquiera concebida o de cualquier forma pensada" (Sosa 1988:351). En este sentido de objetividad se encuentran los filósofos materialistas y muchas formas del realismo, en particular del realismo científico, incluyendo el racionalismo de Descartes.

Dos supuestos básicos de las concepciones fundacionistas han sido atacados: el supuesto metafísico de una realidad constituida por objetos independientes de los sujetos racionales, de sus recursos conceptuales y de sus métodos para conocer esa realidad. Y la concepción de la verdad como correspondencia entre el lenguaje y la realidad (Olivé 1995:108). 
Frente a la posición del realismo metafísico se halla el realismo internalista. Posiciones como la de Kuhn y Putnam concuerdan con un realismo internalista. El supuesto de una realidad independiente que es el punto de partida de las diferencias entre realistas externalistas y realistas internalistas (o entre realismo metafísico y realismo internalista). La clave para entender este desacuerdo está en la noción de objeto (Pérez Ransanz 1999:209).

Siguiendo a Putnam, los objetos no existen independientemente de los esquemas conceptuales, por lo que recortamos al mundo en objetos cuando describimos algún esquema de descripción. Así pues, los objetos dependen existencialmente de los esquemas conceptuales. Esto revela el sinsentido de la idea de objetos autoidentificantes, esto es, de objetos que tienen identidad propia y son independientes de nuestros esquemas conceptuales (Putnam 1981:54).

Para Putnam, los "objetos" son algo que se hace como algo que se descubre, tanto productos de nuestra visión conceptual como del factor objetivo de la experiencia, el factor independiente de nuestra realidad (Pérez Ransanz 1999:209).

A esta noción de objeto se le suma la tesis de la relatividad conceptual que depende del hecho de que los primitivos lógicos y las nociones de objeto y existencia tienen una multitud de usos diferentes y no un significado absoluto. Esta tesis de la relatividad conceptual trae consigo un pluralismo ontológico porque abre la posibilidad de tener concepciones del mundo con ontologías distintas.

Kuhn, por su parte, también es un realista internalista. La noción de Kuhn acerca de la verdad concuerda con la del realismo internalista, ya que decir que un enunciado es verdadero o falso es aceptarlo dentro de un juego de lenguaje, cuyas reglas no permiten aseverar, al mismo tiempo, un enunciado y su contrario (Pérez Ransanz 1999:228). Con las palabras de Kuhn: "declarar un enunciado candidato a verdadero/falso es aceptar un juego de lenguaje cuyas reglas prohíben afirmar a la vez un enunciado y su contrario. Una persona que rompe esta regla, se declara así misma fuera del juego" (Kuhn 2002:124).

Así pues, frente al realismo metafísico de cualquier teoría fundacionista se encuentra el realismo internalista. Posiciones como la de Putnam y Kuhn coinciden en establecer que la noción de objeto depende de nuestros esquemas conceptuales, pero también la realidad impone fuertes constreñimientos a lo que es considerado objeto. Kuhn propone que es posible la comunicación entre marcos inconmensurables y llegar a acuerdos racionales, cuya racionalidad es prudencial.

En conclusión, el fundacionismo que se basa en un realismo metafísico, no da cabida a la racionalidad prudencial, debido al criterio de universalidad que establece hechos autoidentificantes independientes de todo sujeto cognoscente y que mantiene una teoría de la verdad como correspondencia.

En cambio, la teoría de la verdad como aceptabilidad racional es congruente con el realismo internalista y promueve el diálogo entre marcos diferentes y es aquí donde es posible unir la epistemología con la hermenéutica. En la tercera sección, trataremos este aspecto. 


\section{La verdad como adecuación en la teoría de la verdad como aceptabilidad racional y en la hermenéutica filosófica}

a) La verdad como adecuación en la teoría de la verdad como aceptabilidad racional

La teoría de la verdad como aceptabilidad racional (Olivé 2000:196), establece que:

La proposición " $p$ " es un hecho (cuya existencia depende de los marcos conceptuales en los que se puede formular "p").

Con esto se pretende:

i) que " $p$ " es aceptable por cualquier sujeto (epistémico pertinente, en condiciones epistémicas y de diálogo óptimas), y que,

ii) que "p", aquello que expresa " $p$ " es un hecho, en realidad existe.

Las condiciones epistémicas óptimas pueden entenderse como suficientemente buenas o las mejores posibles y también que los sujetos epistémicos tengan recursos conceptuales y materiales adecuados para entender y criticar las razones que pueden ofrecerse a favor o en contra de " $\mathrm{p}$ ".

Según el realismo interno, el mundo no se entiende en el sentido de una realidad objetiva de la tradición platónica, sino como la totalidad de objetos y hechos que no son independientes de los marcos conceptuales. Así pues, las proposiciones, en la teoría de la verdad como aceptabilidad racional, pueden entenderse como adecuadas a un mundo de objetos, pero no como correspondiendo con una realidad dividida y estructurada en hechos y objetos independientes de cada marco conceptual (Olivé 2000:188).

b) La verdad como adecuación en la hermenéutica filosófica

Tradicionalmente se ha entendido la noción de verdad en la hermenéutica filosófica, la aletheía, exclusivamente como desocultación. Sin embargo, la noción de verdad en la hermenéutica gadameriana, tiene que ver con la verdad como adecuación de un enunciado. Veamos.

Gadamer, acerca del enunciado y la verdad dice: "Es la razón misma de las cosas la que se representa y comunica en un modo específico de discurso. Este modo de discurso se llama enunciado, proposición o juicio. La palabra griega que lo designa es apophansis. La lógica posterior lo llamó juicio. El juicio se caracteriza frente a todos los otros modos de discurso por la pretensión de ser verdadero, de revelar un ente tal como es. Se da el mandato, la súplica, imprecación, se da el fenómeno tan enigmático en la interrogación, sobre el que volveremos, se dan innumerables formas de discurso, y todas ellas contienen algo de verdad; pero no se definen exclusivamente por la pretensión de mostrar el ente como es" (Gadamer 2002:53).

Luego, Gadamer establece la relación entre desocultación, verdad y enunciado y dice: “¿Qué clase de experiencia es la que hace consistir la verdad en el discurso mostrante? Verdad es desocultación. Dejar estar lo desocultado, hacerlo patente, es el sentido del discurso. Uno presenta algo que está ahí presente y se comunica a otro tal como está presente para uno. Dice Aristóteles: un juicio es verdadero si deja reunido lo 
que en la cosa aparece reunido; un juicio es falso si hace estar reunido en el discurso lo que en la cosa no está reunido. La verdad del discurso se define, pues, como adecuación del discurso a la cosa, es decir, adecuación del 'dejar estar' el discurso a la cosa presente. De ahí deriva la definición de la verdad divulgada por la lógica: addaequatio intellectus ad rem. Esta definición da como algo obvio que el discurso, es decir, el intellectus que se expresa en el discurso tiene la posibilidad de medirse a sí mismo de forma que lo que alguien dice exprese sólo aquello que hay. A eso llamamos en filosofía la verdad enunciativa, teniendo en cuenta que hay también otras posibilidades de verdad en el discurso. El lugar de la verdad es el juicio" (Gadamer 2002:54).

Para Gadamer, en las ciencias del espíritu, la verdad se encuentra en el enunciado, pero le precede la pregunta, pues: "Un enunciado encuentra su horizonte de sentido en la situación interrogativa, de la que precede" (Gadamer 2002:54).

El concepto de situación sugiere que la pregunta científica y el enunciado científico son un caso especial de una circunstancia general que se encuentra en el concepto de situación. Y es que, no exclusivamente el enunciado es siempre una respuesta y remite a una pregunta, sino que: "la pregunta y la respuesta desempeñan en su carácter enunciativo común una función hermenéutica. Ambos son interpelación" (Gadamer 2002:59).

La interpelación significa que sólo hay verdad en el enunciado en la medida en que éste es interpelación, pues el horizonte situacional que constituye la verdad de un enunciado implica a la persona a la que se dice algo con el enunciado.

Así pues, Gadamer sostiene la tesis de que todo enunciado tiene su horizonte situacional y su función interpelativa, es sólo la base para la conclusión ulterior de que la historicidad de todos los enunciados radica en la finitud fundamental de nuestro ser.

Por útlimo, Jean Grondin dice que: “Incluso si Gadamer no lo dice expresamente, me parece que la fusión de horizontes puede ser entendida como la expresión gadameriana de aquello que la tradición llama la adaequatio rei et intellectus es la adaequatio de la cosa (res) y del comprender (el equivalente del término latino intellectus). [...] Esta verdad más originaria, y que hace posible la adecuación del pensamiento y la cosa, es la del lenguaje mismo (y que él a veces llama la verdad de la palabra) en su capacidad de descubrimiento de las cosas mismas. Es en este sentido que la hermenéutica de la fusión de horizontes se quiere fenomenológica, un descubrimiento del modo en que las cosas ofrecen y de las cosas tal y como éstas se ofrecen" (Grondin 2007:42).

Por lo tanto, la verdad tiene que ver con lo que en la cosa aparece reunido; un juicio es falso si hace estar reunido en el discurso lo que en la cosa no está reunido. Se trata de una verdad fenomenológica. La interpretación de Grondin coincide con la de Gadamer.

Así pues, tanto en la epistemología, como en la hermenéutica, se utiliza el criterio de verdad como adecuación y se trata de una verdad situada. En la epistemología es situada porque depende de los marcos conceptuales más la realidad misma, y dichos marcos se encuentran dentro del acontecer histórico. En la hermenéutica es la adecuación situada porque toma en cuenta a la persona que emite un juicio verdadero dentro de una situación u horizonte hermenéutico. 
Ahora bien, un hecho importante en la teoría de la verdad racional en condiciones epistémicas óptimas es que permite unir a la hermenéutica al auxiliarse de ella para la comprensión de marcos diferentes. Lo mismo sucede con la hermenéutica, su verdad como adecuación está situada, por lo que deben comprenderse diferentes visiones del mundo de manera hermenéutica. Veamos por qué.

\section{De la unión entre epistemología y hermenéutica. De la unión entre racionalidad epistémica y racionalidad prudencial}

La teoría de la verdad como aceptabilidad racional en condiciones epistémicas óptimas promueve un pluralismo epistémico, por lo que se requiere del diálogo y la racionalidad prudencial, para la discusión racional, en la comprensión de marcos inconmensurables. Así pues, la clásica separación entre racionalidad epistémica y racionalidad prudencial ya no se fundamenta, pues ambas se complementan.

Una ventaja de la teoría de la verdad como aceptabilidad racional es que promueve el pluralismo epistémico. Siguiendo a Olivé, el pluralismo promueve el respeto a otros puntos de vista, pero esto no implica que todos valgan igual. Por ello necesitamos distinguir entre objetividad y verdad con el fin de identificar casos en los que existe un consenso racionalmente fundado, pero equivocado. Es decir, cuando la proposición " $p$ " es objetiva, pero no verdadera, por ejemplo, la creencia de que existen razas inferiores. Es posible criticar la creencia racista y demostrar que es falsa. Por ello establece Olivé: "Esto puede requerir que se ofrezcan razones adicionales que quizá tengan que provenir de marcos conceptuales diferentes. De ahí la importancia de las interacciones dialógicas desde marcos conceptuales diferentes. Por eso son cruciales las críticas y las controversias para el desarrollo del conocimiento científico" (Olivé 2000:197).

La interacción dialógica entre marcos diferentes no requiere de la traducción, sino de la interpretación y se lleva a cabo a través de la racionalidad prudencial. Olivé, en El bien, el mal y la razón no establece, sin embargo, que la interacción entre distintos marcos requiere de la racionalidad prudencial, aunque de la cita anterior se infiere lo dicho. En otro de sus libros, titulado Multiculturalismo y pluralismo, Olivé establece, siguiendo a Kuhn que: "La obra de Kuhn sugiere persuasivamente que se debe tomar en serio la idea de que comunidades científicas diferentes, con diferentes paradigmas, es decir, con diferentes concepciones básicas, diferentes estándares de evaluación, diferentes normas metodológicas y diferentes presupuestos metafísicos, viven, en un sentido literal, en mundos distintos. La diversidad conceptual, la diversidad de concepciones del mundo, implica una diversidad de mundos. Kuhn también mostró que admitir todo esto no implica renunciar a la racionalidad científica ni a la racionalidad a secas. Por el contrario, es posible aceptar la diversidad de concepciones del mundo y la diversidad de mundos, y sin embargo, mantener la posibilidad de llegar a acuerdos racionales en el terreno de las concepciones y acciones científicas. El pluralismo sostiene que lo mismo ocurre en las diversas culturas, es posible que sus visiones sean inconmensurables y que los miembros de esas culturas diferentes sean racionales e interactúen racionalmente, que lleguen a acuerdos y que actúen en forma cooperativa y fructífera" (Olivé 1999:112-113).

En las acciones científicas, Karl Popper (1995:71-72), Thomas Kuhn (véase también Pérez-Ransanz 1999:143) y Larry Laudan (1996:147-149), coinciden en proponer que los acuerdos racionales entre marcos diferentes desbordan los límites de las reglas algorítmicas por lo que requieren de una racionalidad sin fundamentos, basada en la racionalidad prudencial. En el caso de las diversas culturas, filósofos como Gadamer (1991: cap. X), Ricoeur (2002) y Vattimo (1995) también están de acuerdo con el hecho de que para comprender culturas ajenas se requiere de la racionalidad prudencial. 
Así pues, podemos establecer que la teoría de la verdad como aceptabilidad racional, al promover un pluralismo epistémico, introduce a la racionalidad prudencial para la comprensión de marcos diferentes. En consecuencia, ambas se complementan. La racionalidad epistémica es objetiva sólo dentro del marco conceptual situado, pero la racionalidad prudencial permite comprender marcos conceptuales diferentes y permite descubrir y entender una palabra o un enunciado extraños.

IV. Epistemología y hermenéutica

De acuerdo con la concepción de la verdad como aceptabilidad racional en condiciones epistémicas óptimas, la verdad de una proposición significa adecuación entre los marcos conceptuales y la realidad, y no puede sostenerse como correspondencia entre enunciado y hecho, puesto que dicha teoría de la verdad como aceptabilidad racional se sustenta en un realismo internalista que se opone al realismo metafísico.

Ahora bien, Kuhn también rechaza la noción de verdad como correspondencia: “lo que está en cuestión fundamentalmente es más bien la teoría de la verdad como correspondencia, la noción de que la meta, cuando se evalúan leyes o teorías científicas, es determinar si se corresponden o no con el mundo externo, objetivo. Yo estoy convencido de que ésta es la noción que, en forma absoluta o probabilista, debe desvanecerse junto con el fundamentalismo." (Kuhn 2002: 119) La principal razón para ir en contra de la teoría de la verdad como correspondencia está en virtud de que el significado y la referencia de los términos es función de la estructura de categorías vigente, en una comunidad, por lo que también se desmiente al realismo metafísico: "Está claro que no puede ser lo que Putnam ha llamado el realismo metafísico. En la medida en que la estructura del mundo puede ser experimentada y la experiencia comunicada, queda condicionada por la estructura del léxico de la comunidad que lo habita" (Kuhn 2002: 125) Y es que la evaluación de un enunciado pretendidamente científico comprende dos partes: en primer lugar, la respuesta a la pregunta ¿es candidato a verdadero o falso? Es léxico dependiente; y en segundo lugar, su aceptabilidad racional depende de un léxico y de las reglas normales de evidencia. Por lo tanto, la referencia es función de la estructura de un léxico o esquema conceptual más las reglas normales de evidencia. En este sentido, no puede haber una verdad conceptual o léxicamente independiente de los marcos conceptuales. Esto es congruente con el realismo interno: no hay categorías ontológicas absolutas, ninguna perspectiva epistémica es privilegiada y "no hay un pegamiento metafísico entre las palabras y las cosas (o entre los enunciados y los hechos)" (Pérez Ransanz 1999:227).

Kuhn, sin embargo, reconoce que la idea de verdad cumple la función de exigir la aceptación o el rechazo de ciertos enunciados, o teorías, de acuerdo con la evidencia compartida: "Función que refleja el supuesto, implícito en toda evaluación, de que nuestros juicios empíricos son candidatos a tener un valor de verdad. De aquí que para dar cuenta de este tipo de situaciones epistémicas Kuhn proponga concebir la verdad como un juego de lenguaje, 'el juego de lo verdadero/falso', donde rigen ciertas reglas lógicas mínimas entre las que destacan el principio mínimo de no contradicción-, las cuales son un prerrequisito de la racionalidad de las evaluaciones" (Pérez Ransanz 1999:227). Así pues, dice Kuhn: “En esta reformulación, declarar un enunciado candidato a verdadero/falso es aceptar un juego de lenguaje cuyas reglas prohíben afirmar a la vez un enunciado y su contrario" (Kuhn 2002:124).

Según Kuhn, cuando los lenguajes de dos comunidades son diferentes entre sí, o difieren en su estructura, habrá secuencias de palabras que expresen afirmaciones diferentes para los miembros de dichas comunidades. Así pues, un enunciado puede ser candidato a verdadero o falso en un léxico y no serlo en el 
otro; además, en caso de que lo sea, puede diferir el resultado de su evaluación.

La teoría de la verdad kuhniana es congruente con un realismo internalista que excluye la verdad como correspondencia metafísica, pues compromete con un isomorfismo entre nuestras representaciones y la realidad independiente y con la idea de objetos autoidentificantes, de cosas en sí, que es incompatible con las tesis internalistas. Sin embargo, el mundo no es pura creación mental porque el objeto intencional de nuestros juicios es lo que está en la base de aceptarlos o rechazarlos frente a la evidencia disponible, exigencia que quedaría recuperada en un juego de lenguaje.

Como podemos observar, la verdad como aceptabilidad racional en condiciones epistémicas óptimas es congruente con la noción de verdad kuhniana, ambas sustentan que un enunciado es verdadero en función de los marcos conceptuales y de la evidencia disponible y también sostienen que la verdad no es correspondencia entre enunciado y hecho, sino adecuación entre marco conceptual y realidad objetiva.

La teoría de la verdad como aceptabilidad racional, al ser congruente con la noción de verdad kuhniana, requiere, por tanto, de la misma solución que propone Kuhn para la comparación entre enunciados inconmensurables. Veamos.

León Olivé establece que la teoría de la verdad como aceptabilidad racional promueve un pluralismo epistémico, pues reconoce que la verdad puede ser diferente para cada comunidad epistémica, pero esto no impide que pueda llegar a un acuerdo racional entre dichos marcos a partir del diálogo. Si esto es así, entonces debemos ser congruentes con las ideas de Kuhn acerca de cómo entender una secuencia de palabras que no son congruentes con determinada estructura, es decir, cómo entender un enunciado que resulta inconmensurable entre dos marcos diferentes. La traducción sería lo más accesible para los sujetos que intentan comprenderse, pero en este caso no es suficiente, puesto que dicho enunciado es una entidad que no existe en el lenguaje $y$ en el mundo al que se intenta traducir, por lo que los léxicos no son congruentes y la traducción no basta.

De acuerdo con Kuhn, sin embargo, siempre es posible lograr la comprensión y comunicación a través de la interpretación y aprendizaje del lenguaje. Como señala Pérez Ransanz, siguiendo a Kuhn, estos procesos no son misteriosos, los antropólogos e historiadores los utilizan cotidianamente.

Según Kuhn, la construcción de un lenguaje requiere detectar los términos interconectados que han cambiado de significado y descubrir a través de hipótesis interpretativas el uso que tienen ciertos términos en el original (Pérez Ransanz 1999:103). Kuhn supone un principio de inteligibilidad universal que lo compromete con un supuesto muy fuerte de racionalidad, pero distinto del de traducibilidad (Pérez Ransanz 1999:106).

El científico para aprender un lenguaje requiere, en primer lugar, que una parte del vocabulario complementario esté bien asimilado; en segundo lugar, en el proceso de adquisición de los términos nuevos, las definiciones cumplen un papel mínimo, pues los términos se transmiten mostrando las situaciones en las que se aplican, esto es, a través de ejemplos interparadigmáticos de su uso.

Dicha tarea se transmite por un experto que domina la nueva teoría y consiste en demostraciones directas 
en el laboratorio, o en descripciones de aplicaciones donde se utiliza el vocabulario familiar, pero intercalando los términos por aprender; así pues, "en esta tarea es indispensable un componente ostensivo o estipulativo (...) las palabras se tienen que aprender junto con las situaciones donde funcionan, y las estipulaciones afectan tanto al mundo como al lenguaje. Por este motivo señala Kuhn que las palabras y la naturaleza se aprenden juntas" (Pérez Ransanz 1999:106).

En tercer lugar, para que el estudiante pueda aprender un lenguaje o término se requiere de ejemplos de semejanza/diferencia. Esto permite que el estudiante logre identificar los referentes de los nuevos términos a través de objetos o situaciones que forman un conjunto de contraste. Los ejemplos de semejanza/diferencia son propios de una taxonomía. Por ejemplo, para aprender el término 'líquido' en un lenguaje no técnico, uno debe dominar los términos gas y sólido, de aquí que se tienen que aprender a la vez y formar un conjunto de contraste. (Pérez Ransanz 1999:112) Un ejemplo muy sencillo lo proporciona Kuhn acerca de cómo un niño aprende a distinguir entre un cisne, un pato y un ganso durante un paseo con su padre en el zoológico: "Durante el paseo, se ha reprogramado parte del mecanismo neural por el cual el niño procesa estímulos visuales, y se han modificado los datos que recibe de los estímulos que antes le hacían evocar 'aves'. Cuando empezó su paseo, el programa neural hizo destacar las diferencias entre cada uno de los cisnes y también entre éstos y los gansos. Hacia el final del paseo, se destacaban caracteres como longitud y la curvatura del cuello de los cisnes, se habían suprimido otros, a la vez que diferían de los datos relativos a los gansos y a los patos, de manera que no había ocurrido antes. Las aves que en un principio había visto iguales -y también diferentes- estaban agrupadas ahora en conglomerados distintos dentro del espacio perceptual" (Kuhn 1996: 334).

En cuarto lugar, en el aprendizaje del lenguaje se forman expectativas respecto de las propiedades y comportamiento de los referentes de los términos. Se aprenden generalizaciones de proyecciones sobre fenómenos futuros aún no examinados. También es cierto que quienes aprenden un lenguaje pueden aprender rutas de aprendizaje distintas, aunque no tienen confusión en cuanto al referente, todos ubican el mismo objeto (Pérez Ransanz 1999:113).

Las implicaciones del análisis del aprendizaje de un lenguaje, siguiendo a Kuhn son:

-Al cambiar un léxico, puede cambiar el significado de un término o conjunto de términos interrelacionados.

-El hecho de que los referentes de los términos se aprendan a reconocer mediante ejemplos de semejanza/diferencia "pone en claro que no es necesario contar con una lista de propiedades necesarias y suficientes para determinar la referencia de un término" (Pérez Ransanz 1999:115).

-Además, como los términos de clase no tienen significado individualmente, sino sólo a través de ligas con otros términos, su significado no se podría reducir a propiedades definitorias.

-El papel que cumplen los vínculos semánticos revela que la referencia no es independiente del significado: “Cuando Kuhn objeta a quienes piensan que la referencia de un término como 'agua' es inmune a todos los cambios que ha sufrido el concepto en la teoría y en la manera de elegir las instancias de esta sustancia, argumenta que no sólo el sentido o modo de uso de un término sino también '(su) referencia es una función de la estructura compartida del léxico' (Pérez Ransanz 1999:115). Esto es, la estructura léxica, al determinar 
los vínculos semánticos entre los términos -vínculos de contraste o vínculos legales- determina a la vez su referencia" (Pérez Ransanz 1999:115). Con las palabras de Kuhn: "Un enunciado puede ser candidato a verdadero/falso en un léxico sin tener este estatus en otros. [...] En la medida en que la estructura del mundo puede ser experimentada y la experiencia comunicada, queda condicionada por la estructura del léxico de la comunidad que lo habita" (Kuhn 2002:125)

En conclusión, aprender un enunciado inconmensurable a partir de ejemplos semejanza/diferencia no implica que no se esté identificando su referente, puesto que el lenguaje y el mundo se aprenden juntos y depende de la estructura de cada marco, pero en cada estructura se tienen patrones de semejanza/diferencia que permiten identificar un referente.

Pues bien, a partir de Kuhn podemos establecer que es posible identificar referentes de términos inconmensurables entre marcos diferentes, con base en aprender un lenguaje a través de ejemplos de semejanza/diferencia, puesto que es posible que en un lenguaje diferente se retomen ejemplos congruentes o inteligibles con el marco que se está comparando, después de todo, la inconmensurabilidad es local.

Esto sucede justamente en la hermenéutica. Los significados tienen un lenguaje que es propio de cada léxico. En cada léxico es posible a partir de ejemplos de semejanza/diferencia para comprender una entidad inexistente, y al reconocerla podemos decir, en la hermenéutica, que se descubre lo oculto, algo que no se conoce en un lenguaje. Veamos.

La actitud receptiva gadameriana parte del reconocimiento de la falibilidad y finitud del intérprete que busca aprender cosas nuevas y diferentes y aun contradictorias a sus creencias y prejuicios familiares (Velasco Gómez 2000:159).

Esta actitud reflexiva mantiene la prioridad del valor heurístico del descubrimiento sobre el de la justificación. Como señala Velasco Gómez: “Es importante enfatizar que el descubrimiento, el encuentro con lo extraño tiene una relevancia epistemológica sólo si el intérprete está abierto y alerta para incorporarles a sus creencias y saberes previamente adquiridos con el propósito de ponerlos en cuestionamiento" (2000:159).

Dicha confrontación es el rasgo esencial de la hermenéutica. La confrontación entre lo familiar y lo extraño descubierto, plantea la necesidad de buscar un equilibrio analógico entre lo propio y lo extraño: "Entre los aspectos subjetivos que aporte el intérprete desde sus prejuicios y contenidos objetivos que ofrece el texto. La postura de Gadamer se opone a un subjetivismo posmoderno que anula toda pretensión de objetividad y verdad, como a un objetivismo positivista que usurpa al sujeto la responsabilidad de juzgar y diluye la objetividad en metodologías rigurosas (Velasco Gómez 2000: 160).

El punto analógico de equilibrio de lo propio y lo extraño se expresa en la metáfora gadameriana de fusión de horizontes como rasgo distintivo de la comprensión. La fusión del encuentro entre el presente familiar y la alteridad del pasado no es algo que se logra automáticamente: "Se requiere siempre del juicio prudencial del intérprete que ante las contradicciones entre los prejuicios y los nuevos significados descubiertos pondera qué deja de lo propio y qué retoma de lo ajeno. Este juicio prudencial tiene para Gadamer el carácter de la racionalidad práctica de la phrónesis aristotélica" (Velasco Gómez 2000: 160). 
Por otra parte, la objetividad en Gadamer parte de lo aceptado intersubjetivamente por una comunidad. Sin embargo, la objetividad, según este filósofo, no es algo fijo y dado socialmente, sino que dicha noción de objetividad incluye la alteridad de lo que no es familiar. La alteridad no es algo que se pueda someter al método científico, sino algo que se comprende dialógicamente. A través de la comprensión dialógica de lo extraño se cuestionan las creencias familiares, de manera que la objetividad dada en cierta situación puede desarrollarse de manera ampliativa, incluyente y progresiva (Gadamer 1991:363, Velasco Gómez 2001:232233).

Como podemos observar, la objetividad en la comparación de marcos inconmensurables es análoga en la hermenéutica gadameriana y en la filosofía de la ciencia kuhniana. En la primera se parte de la objetividad situada, cuya confrontación con lo extraño genera un diálogo que da lugar a la amplitud incluyente y progresiva. En Kuhn, por su parte, la confrontación entre marcos inconmensurables requiere de aprender un léxico a través de ejemplos de semejanza/diferencia; al confrontar la objetividad, también situada de la estructura del paradigma con un objeto extraño, se aprende un mundo nuevo. Por lo que, tanto en la hermenéutica, como en la filosofía de la ciencia hay una manera análoga de conocer mundos nuevos.

Ahora bien, los enunciados inconmensurables, en la filosofía de la ciencia kuhniana, o extraños, en la hermenéutica gadameriana, una vez que han sido comprendidos, es posible reconocerlos como verdaderos, según la teoría de la verdad como aceptabilidad racional, puesto que pueden ser sometidos a la objetividad de las razones objetivamente suficientes y lograr un consenso racional situado.

Podemos considerar lo anterior, puesto que la teoría como aceptabilidad racional ya no excluye lo que excluye la teoría de la verdad como correspondencia cimentada en un realismo metafísico: la fuerza de convicción que emana del mundo percibido por una comunidad de seres humanos, pues lo conocido depende de cierto marco conceptual, aunque la realidad impone fuertes constreñimientos a lo que es considerado verdadero. Dicho hermenéuticamente, la teoría de la verdad como aceptabilidad racional acepta el mundo porque los objetos científicos que elabora son las determinaciones del mundo que percibe; en el horizonte de ese mundo es como su investigación es intramundana, también es en dicho mundo donde se sitúan los objetos culturales que constituyen recursos conceptuales y materiales adecuados para entender y criticar las razones que puedan tenerse a favor o en contra de " $p$ ".

En conclusión, la distinción tradicional entre hermenéutica y epistemología actualmente no se fundamenta. Tampoco se requiere sustituir a la epistemología por la hermenéutica, sino que más bien, la epistemología se complementa con la hermenéutica. Todo lo anterior es posible sólo si partimos de la teoría de la verdad como aceptabilidad racional en condiciones epistémicas óptimas. Así pues, dicha teoría permite justificar lo conmensurable como entender lo inconmensurable.

\section{Bibliografía}

Di Gregori, M.C. 1995. La fundamentación racional del conocimiento: Programas fundacionistas. En: L. Olivé (ed.). Racionalidad epistémica. Madrid: Trotta, pp. 41-58.

Kuhn, T. S. 1996. La tensión esencial. Estudios selectos sobre la tradición y el cambio científico. México: Fondo de Cultura Económica-CONACYT. 
Kuhn, T. S. 2002. El camino desde la estructura. Barcelona: Paidós.

Gadamer, H. G. 1985. La razón en la época de la ciencia. Madrid: Alfa.

Gadamer, H. G. 1991. Verdad y método. Salamanca: Sígueme.

Gadamer, H. G. 2002. Verdad y método II. Salamanca: Sígueme.

Grondin, J., 2007. La fusión de horizontes ¿La versión gadameriana de la Adaequatio rei et intellectus? En: M. Aguilar Rivero y M. A. González Valerio. Gadamer y las humanidades I. México: UNAM, pp. 23-42.

Laudan, L. 1996. Beyond positivism and relativism: Theory, method and evidence. Oxford: Westvick Press.

Olivé, L. (ed). 1995. Racionalidad epistémica. Madrid: Trotta.

Olivé, L.1999. Multiculturalismo y pluralismo. México: Paidós-UNAM.

Olivé, L. 2000. El bien, el mal y la razón. Facetas de la ciencia y la tecnología. México: Paidós-UNAM.

Pérez Ransanz, A. R. 1999. Kuhn y el cambio científico. México: Fondo de Cultura Económica.

Popper, K. 1995. El mito del marco común. Barcelona: Paidós.

Putnam, H. 1981. Reason, Truth and History. Cambridge: University Press.

Ricoeur, P. 2002. Del texto a la acción. México: Fondo de Cultura Económica.

Rorty, R. 1979. Philosophy and the Mirror of Nature. Princeton: Princeton University Press.

Sosa, E. 1988. Filosofía en serio y libertad de espíritu. En: L. Olivé (comp.). Racionalidad. Ensayos sobre la racionalidad en ética y política, ciencia y tecnología. México: UNAM-Siglo XXI, pp. 350-374.

Vattimo, G. 1995. Más allá de la interpretación. Barcelona: Paidós.

Velasco Gómez, A. 2000. Tradición y comprensión reflexiva. En: Beuchout, M. y Velasco, A. (comps.). Perspectivas y horizontes de la hermenéutica en las humanidades, el arte y la ciencia. México: UNAM, pp. 157-164.

Velasco Gómez, A. 2001. La relevancia del pensamiento de Gadamer en la filosofía, a la vuelta del tercer milenio: más allá de la modernidad y la posmodernidad. Intersticios 6(14-15): 227-240.

Recibido el 4 Ago 2009

Aceptado el 28 Nov 2009 